\title{
SISTEMAS DE RESFRIAMENTO EVAPORATIVO E O DESEMPENHO DE FRANGOS DE CORTE
}

\author{
Valmir Sartor ${ }^{1 *}$; Fernando da Costa Baêta'; Maira Luciana Luz²; Roberto Carlos Orlando² \\ ${ }_{2}^{1}$ Depto. de Engenharia Agrícola - UFV, R. P. H. Rolfs s/n, CEP: 36571-000 - Viçosa, MG. \\ ${ }^{2}$ Pós-Graduando do Depto. de Engenharia Agrícola - UFV. \\ ${ }^{3}$ Estagiária - UFV. \\ *Autor correspondente <vsartor@mail.ufv.br>
}

\begin{abstract}
RESUMO: As condições térmicas no interior de instalações para frangos de corte tem importância vital para o sucesso desta atividade. Desta forma, deve-se buscar o conforto térmico para as aves com o mínimo custo em materiais, equipamentos e energia. Baseado nisto foi desenvolvido um trabalho com o objetivo de avaliar 0 efeito de três sistemas de resfriamento evaporativo no desempenho de frangos de corte. Para isso, utilizou-se um galpão dividido em quatro partes nas quais foram instaladas os tratamentos: ventilador associado a nebulização (VNB), ventilador de alta rotação associado a nebulização (VNA), nebulização (NEB) e nebulização acoplada ao ventilador (NEV). Foi registrado o consumo de ração, o ganho de peso e a mortalidade, obtendose assim a conversão alimentar. Os sistemas de resfriamento evaporativo (VNA e VNB) proporcionaram os melhores resultados com os maiores valores de ganho de peso por ave e os menores valores de conversão alimentar e mortalidade. Resultados menos satisfatórios foram observados no NEV, com os menores valores de ganho de peso por ave e maiores valores de conversão alimentar e mortalidade.

Palavras-chave: ambiente térmico, conforto térmico, ventilação, aviário
\end{abstract}

\section{EVAPORATIVE COOLING SYSTEMS AND THE PERFORMANCE OF BROILERS}

\begin{abstract}
The thermal conditions inside poultry houses are very important for the success of this business. It is however necessary to have an adequate animal thermal confort and a minimum cost of material, equipment and energy. This experiment was carried to verify the effect of evaporative cooling systems on the performance of poultry. The building was divided in four equal sectors. The treatments consisted of ventilator and spraying system (VNB), high rotation ventilator and spraying system (VNA), spraying system (NEB), and spraying system connected to the ventilator (NEV). Feed intake, weight gain, mortality of poultry were recorded and the food conversion calculated. It is shown the evaporative cooling systems (VNA e VNB) presented the best results, increasing weight gain with lower values of food conversion and mortalily. The worst results were found for the spraying system connected to the ventilator (NEV).

Key words: thermal environment, thermal confort, ventilation, poltry house
\end{abstract}

\section{INTRODUÇÃO}

A avicultura de corte tem apresentado, nas últimas décadas, elevado desenvolvimento tecnológico. No início dos anos 80, um frango com 70 dias de idade atingia, aproximadamente, $2,0 \mathrm{~kg}$ de peso vivo, com conversão alimentar média de 3,5 ( $\mathrm{kg}$ de ração $\mathrm{kg}^{-1}$ de peso vivo). Atualmente em apenas 42 dias, é possível obter frangos com 2,3 kg de peso vivo e conversão alimentar de 1,80 (Tendências, 1995). Como causas desse avanço podemos citar o melhoramento genético, a nutrição, a sanidade, o manejo das aves e melhoria nas instalações. Algumas conseqüências desse avanço tem sido problemas cardíacos e pulmonares (Matias \& Patarra 1995). Os quais podem, no entanto, ser amenizados, desde que as aves sejam criadas em condições ambientais apropriadas.

A ave é um animal que se adapta melhor a ambientes frios, pois seu sistema termo-regulador é mais adequado para reter calor do que para dissipá-lo. Quando exposta ao estresse térmico, por elevadas temperaturas, a ave apresenta uma queda no consumo de ração e, em conseqüência, redução no ganho de peso e pior conversão alimentar (Müller, 1982).

Segundo Campos (1995), os altos valores de temperatura ambiente vêm provocando queda de produção e mortalidade elevada no meio avícola. Tal fato vem se agravando à medida em que se aumenta a densidade de criação e, também, pelo fato de que a ave vem sendo melhorada geneticamente e se torna mais precoce e produtiva (Macari, 1998).

O ambiente térmico representado por temperatura, umidade, velocidade do ar e radiação, cujo efeito combinado pode ser quantificado pelo índice de temperatura de globo e umidade (ITGU), afeta diretamente as aves, comprometendo sua função vital mais importante, que é a manutenção de sua homeotermia. Teixeira (1983) encontrou o valor do ITGU igual a 76 como limite crítico superior para frangos de corte de 21 a 50 dias de idade, com base no consumo de ração e no ganho de peso. Em condições de verão têm-se verificado, no interior dos aviários, valores de 
ITGU acima de 76, o que inibe o desempenho produtivo das aves e, constitui-se em um dos principais problemas para sua criação (Curtis, 1983). Nesse caso, as limitações climáticas podem ser amenizadas a partir de um projeto de instalação adequado em conjunto com alimentação e manejo racional, bem como técnicas de modificações térmicas ambientais (Curtis, 1983; Rivero, 1985).

Uma técnica de modificação ambiental artificial bastante difundida é o resfriamento evaporativo do ar, que consiste em incorporar vapor d'água diretamente no ar, causando mudança no seu ponto de estado (aumento da umidade e reduzindo a temperatura). Esta técnica deve preferencialmente ser associada a sistemas de ventilação o que, além de facilitar o controle da umidade no interior da instalação, proporciona uma melhor renovação do ar no interior da mesma. Segundo Mcneill et al. (1983) e Wiersma \& Short (1983), em instalações agrícolas esse sistema é considerado mais vantajoso por apresentar baixo custo inicial e baixo custo operacional.

Com base no exposto, foi desenvolvido um experimento com o objetivo de avaliar o efeito de quatro sistemas de resfriamento evaporativo em aviário para frangos de corte empregando-se: ventilador associado a nebulização, ventilador de alta rotação associado a nebulização, nebulização e ventilador com sistema de nebulização acoplado, tendo como base as respostas fisiológicas das aves (ganho de peso, conversão alimentar e mortalidade).

\section{MATERIAL E MÉTODOS}

O trabalho experimental foi realizado durante 0 período de 02 a 28 de fevereiro de 1996, em um aviário, localizado no Município de Céu Azul, PR, a uma latitude de $25^{\circ} 33^{\prime}$, sul, longitude de $54^{\circ} 34^{\prime}$, oeste, com altitude de $616 \mathrm{~m}$. O clima da região, de acordo com a classificação de KÖPPEN, é Ccf (quente, temperado, chuvoso, constantemente úmido).

O aviário utilizado apresentava dimensões de 100 $\mathrm{m} \times 12 \mathrm{~m}$; pé-direito de $3 \mathrm{~m}$; mureta lateral de $0,30 \mathrm{~m}$ de altura; piso de chão batido; aberturas laterais com tela hexagonal de 0,025 m e cortinas de plástico; cobertura de telhas cerâmica francesa, com pintura de cor branca (cal) na face externa, em duas águas, com inclinação de 50\%; beirais de $0,80 \mathrm{~m}$; não provido de lanternim, porém possuindo 12 tubos de alívio, de $0,50 \mathrm{~m} \times 0,50 \mathrm{~m}$ de abertura, distribuídos ao longo da cumeeira; e orientação do eixo longitudinal na direção Leste - Oeste.

O número de aves alojadas foi de 13000 , da linhagem Hubbard, com uma densidade de aproximadamente 11 aves por metro quadrado. A coleta de dados iniciou-se quando as aves possuíam 20 dias de idade e $1,10 \mathrm{~kg}$ de peso vivo e foi concluída aos 48 dias de idade das aves e média de aproximadamente $2,60 \mathrm{~kg}$ de peso vivo.

$\mathrm{O}$ aviário foi dividido, no sentido longitudinal, em quatro partes iguais obtendo-se assim quatro unidades experimentais distintas. Utilizou-se para isto lona plástica preta vedando-se desde o chão até a cobertura. Foram distribuídos quatro diferentes sistemas de resfriamento evaporativo: ventilador associado a nebulização (VNB), ventilador de alta rotação associado a nebulização (VNA), nebulização (NEB) e ventilador acoplado ao nebulizador (NEV).

O sistema de nebulização era composto por uma bomba de alta pressão que pressurizava a água através de tubos de PVC, com diâmetro de $20 \mathrm{~mm}$, dispostos em três linhas longitudinais, com bicos nebulizadores a cada $2 \mathrm{~m}$ e posicionados à $3,50 \mathrm{~m}$ de altura. Os ventiladores utilizados no sistema VNB eram axiais, com seis pás, modelo AVIPAL, $540 \mathrm{rpm}, 1 \mathrm{~m}$ de diâmetro, vazão de $300 \mathrm{~m}^{3} \mathrm{~min}^{-1}$ e motor de indução bifásico de $368 \mathrm{~W}$. No sistema VNA utilizaramse ventiladores axiais com três pás, modelo CLIMAX-S AVIMEC, 1130 rpm, $1 \mathrm{~m}$ de diâmetro, vazão de $330 \mathrm{~m}^{3}$ min ${ }^{1}$ e motor de indução bifásico de $368 \mathrm{~W}$. O sistema NEV era composto de ventiladores axiais, com seis pás, modelo $\mathrm{PHM}$ 350/10 ROOSTER S.A., 540 rpm, diâmetro de 1 m, vazão de $350 \mathrm{~m}^{3} \mathrm{~min}^{-1}$ e motor de indução bifásico de $736 \mathrm{~W}$.

Foram instalados dois ventiladores em cada área experimental, distribuídos a cada $12,5 \mathrm{~m}$, na lateral do galpão, a favor do vento dominante e a 1,50 m do chão, com $10 \%$ de inclinação para baixo. Os sistemas de ventilação permaneceram em funcionamento enquanto a temperatura do ar fosse superior a $25^{\circ} \mathrm{C}$, comandados por termostatos. Os sistemas de umidificação, comandados por umidostatos, foram acionados quando os ventiladores estavam ativados e a umidade relativa do ar fosse inferior a $75 \%$, no interior de cada área experimental.

Foram registrados semanalmente o consumo de ração (CR), o ganho de peso (GP) - por amostragem de 40 frangos - e a mortalidade (MO). A conversão alimentar (CA) foi calculada, a partir dos dados de ganho de peso e conversão alimentar.

O delineamento experimental foi inteiramente casualizado, com quatro tratamentos e quatro repetições (Mendenhall \& Sincich, 1992). As repetições eram função da idade das aves, ou seja, 27 dias, 34 dias, 41 dias e 48 dias de idade das aves.

Os resultados das variáveis acima foram interpretados por análise de variância e de regressão. As médias dos fatores qualitativos foram comparadas pelo teste F e, ou, teste de Tukey, adotando-se níveis de 1 e $5 \%$.

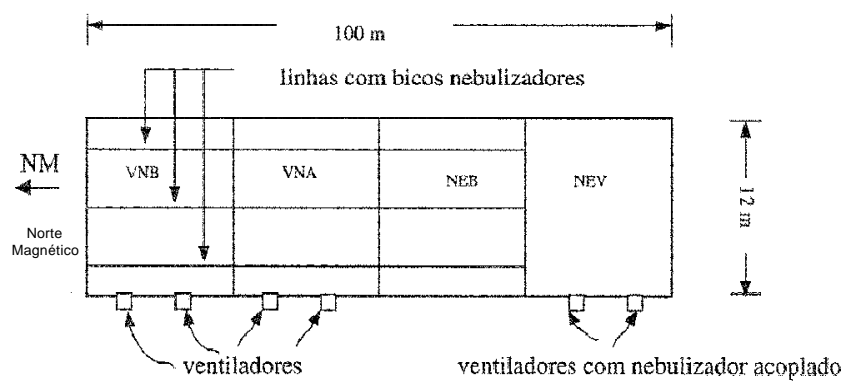

Figura 1 - Esquema da divisão do aviário demonstrando a distribuição dos tratamentos - ventilador associado a nebulização (VNB), ventilador de alta rotação associado a nebulização (VNA), nebulização (NEB) e ventilador acoplado ao nebulizador (NEV) - e a distribuição dos equipamentos de ventilação e resfriamento. 


\section{RESULTADOS E DISCUSSÃO}

A TABELA 1 apresenta os resumos das análises de variância referentes aos efeitos dos tratamentos experimentais $(T)$ - ventilador associado a nebulização (VNB), ventilador de alta rotação associado a nebulização (VNA), nebulização (NEB) e nebulização acoplada ao ventilador (NEV), com quatro repetições (em função da idade) com relação ao consumo de ração $(\mathrm{CR})$, ao ganho de peso (GP), à conversão alimentar (CA) e à mortalidade (MO) das aves.

Observa-se, na TABELA 1, que para todas as variáveis analisadas, consumo de ração $(\mathrm{CR})$, ganho de peso (GP), conversão alimentar (CA) e mortalidade (MO) houve diferença significativa entre os tratamentos $(T)$ a $1 \%$ de probabilidade.

Nas TABELAS 2, 3, 4 e 5 encontram-se as médias dos tratamentos com relação ao consumo de ração $(\mathrm{CR})$, ganho de peso (GP), conversão alimentar (CA), e mortalidade $(\mathrm{MO})$ respectivamente.

Os maiores valores de consumo de ração ocorreram no tratamento NEV, com $5,30 \mathrm{~kg}_{\text {frango }}{ }^{-1}$ (TABELA 2). Este maior consumo ocorreu, provavelmente, pela maior mortalidade observada neste tratamento (TABELA 5). Uma vez que o consumo foi obtido pela

TABELA 1 - Análise de variância referente ao efeito dos tratamentos $(T)$, sobre o consumo de ração $(\mathrm{CR})$, o ganho de peso (GP), a conversão alimentar (CA) e a mortalidade (MO) das aves.

\begin{tabular}{lrcccc}
\hline Fontes de & \multicolumn{5}{c}{ Quadrado Médio } \\
\cline { 2 - 6 } Variação & GL & GP & CR & CA & MO \\
\hline T & 3 & $29,2083^{*}$ & $35,3644^{*}$ & $0,1170^{*}$ & $10,6361^{*}$ \\
Resíduos & 12 & 2,8580 & 4,3245 & 0,0102 & 1,5860 \\
\hline CV (\%) & & 4,55 & 8,33 & 4,37 & 24,00 \\
\hline
\end{tabular}

*Significativo a $1 \%$ pelo teste $\mathrm{F}$.

TABELA 2 - Valores médio do consumo de ração (CR) para os tratamentos.

\begin{tabular}{|c|c|c|c|c|}
\hline Tratamentos & VNB & VNA & NEB & NEV \\
\hline $\mathrm{R}(\mathrm{kg}$ frango-1) & $5,08 \mathrm{~b}$ & $5,12 b$ & $5,12 b$ & $5,30 \mathrm{a}$ \\
\hline
\end{tabular}

Média seguidas de pelo menos uma mesma letra minúscula, na linha, não diferem, pelo teste de Tukey a 5\%.

TABELA 3 - Valores médios do ganho de peso dos frangos (GP) e do peso das aves no abate referentes aos tratamentos.

\begin{tabular}{lcccc}
\hline Tratamentos & VNB & VNA & NEB & NEV \\
\hline GP $\left(\mathrm{g} \mathrm{dia}^{-1}\right)$ & $55,1 \mathrm{ab}$ & 56,4 a & 54,5 bc & $53,2 \mathrm{c}$ \\
\hline
\end{tabular}

Média seguidas de pelo menos uma mesma letra minúscula, na linha, não diferem, pelo teste de Tukey a $5 \%$.
TABELA 4 - Valores médios da conversão alimentar (CA) referentes aos tratamentos.

\begin{tabular}{lcccc}
\hline Tratamentos & VNB & VNA & NEB & NEV \\
\hline CA & $1,96 a$ & 1,93 a & 2,00 a & 2,12 b \\
\hline
\end{tabular}

Média seguidas de pelo menos uma mesma letra minúscula, na linha, não diferem, pelo teste de Tukey a $5 \%$.

TABELA 5 - Valores totais da mortalidade (MO) para os tratamentos.

\begin{tabular}{cccc}
\hline VNB & VNA & NEB & NEV \\
\hline 4,66 b & $3,99 \mathrm{~b}$ & $4,69 \mathrm{~b}$ & $7,64 \mathrm{a}$ \\
\hline
\end{tabular}

Média seguidas de pelo menos uma mesma letra minúscula, na linha, não diferem, pelo teste de Tukey a $5 \%$.

razão entre 0 total de ração consumida pelo peso total das aves aos 48 de idade (quando foram encaminhadas para 0 abate).

Nas TABELAS 3 e 4 verificam-se diferenças significativas entre os tratamentos, sendo que os tratamentos VNA e VNB apresentaram os melhores resultados, proporcionando os maiores valores de ganho de peso e os menores valores de conversão alimentar. Isso ocorreu, provavelmente, pelas melhores condições térmicas ambientais nestes tratamentos, em virtude de uma melhor renovação de ar e melhor eficiência do sistema de umidificar e resfriar evaporativamente 0 ar insuflado no interior do galpão, reduzindo assim menores os valores do índice de temperatura de globo e umidade (ITGU) e da carga térmica radiante (CTR) (Baêta \& Souza, 1997; Sartor, 1997). Os piores resultados foram observados no sistema NEV, proporcionando os menores valores de GP e os maiores valores de CA e, conseqüentemente, os maiores níveis de desconforto térmico para as aves (maiores valores de ITGU e CTR), possivelmente, pela pequena quantidade de água aplicada ao ar pelos nebulizadores e constante renovação de ar pelo ventilador.

Os maiores valores de mortalidade $(7,64 \%)$ foram observados no sistema NEV (TABELA 5). Como já mencionado anteriormente, isso provavelmente ocorreu pela pequena quantidade e má distribuição da água aplicada pelos nebulizadores ao ar e constante renovação deste pelos ventiladores. Desta forma, o sistema não foi eficiente em reduzir e uniformizar os valores de ITGU e da CTR, nos horários de maior desconforto térmico ambiental, promovendo gradientes térmicos no interior do tratamento. Isso contribuiu para o aumento da mortalidade pela aglomeração das aves, nos locais de melhores condições ambientais. Os demais tratamentos, VNB, VNA e NEB, apresentaram desempenhos semelhantes, não apresentando diferenças estatísticas entre si. 


\section{CONCLUSÕES}

Os sistemas de resfriamento evaporativo com ventilador associado a nebulização (VNA e VNB) proporcionaram os melhores resultados, ou seja, maiores valores de ganho de peso e menores valores de conversão alimentar e de mortalidade. Os resultados menos satisfatórios foram observados no NEV.

\section{REFERÊNCIAS BIBLIOGRÁFICAS}

BAÊTA, F. C.; SOUZA, C. F. Ambiência em edificações rurais: conforto animal. Viçosa: UFV, 1997. 246p.

CAMPOS, E.J. Programa de alimentação e nutrição para aves de acordo com o clima - Reprodutoras. In: SIMPÓSIO INTERNACIONAL SOBRE AMBIÊNCIA E INSTALAÇÃO NA AGRICULTURA INDUSTRIAL, Campinas, 1995. Livro de textos. Campinas: FACTA, 1995. p.251-257.

CURTIS, S.E. Environmental management in animal agriculture. Ames: The lowa State University Press, 1983. 409p.

MACARI, M. O frango adensado. Globo Rural, v.13, n. 150, 1998. p.48-54.

McNEILL, S.G.; FEHR, R.L.; WALKER, J.N.; PARKER, G.R. Performance of evaporative coolers for mid-south gestation housing. Transactions of the ASAE, v.26, p.219-222, 1983.
MATIAS, I.; PATARRA, P. Genética: a invasão dos pintos avós e sua fórmula secreta. Revista Avicultura Industrial, n.9, p.34-60, 1995.

MENDENHALL, W., SINCICH, T. Statisctics for engeneering and the sciences. 3. ed. San Francisco: Dellen Publishing Company, 1992 . 963p.

MÜLLER, P.B. Bioclimatologia aplicada aos animais domésticos. Porto Alegre: Sulina, 1982. 158p.

RIVERO, R. Arquitetura e clima: acondicionamento térmico natural. 2.ed. Porto Alegre: D.C. Luzatto, 1985. 240p.

SARTOR, V. Efeito do resfriamento evaporativo e da ventilação forçada no conforto térmico ambiental de verão, em maternidade de suínos. Viçosa, 1997. 76p. Dissertação (Mestrado) - Universidade Federal de Viçosa.

TENDÊNCIAS de consumo: este ano mais frangos e ovos no dia-a-dia. Guia aves e ovos, p. 8-48, 1995.

TEIXEIRA, V.H. Estudo dos índices de conforto em duas instalações de frango de corte para as regiões de Viçosa e Visconde do Rio Branco - MG. Viçosa, 1983. 62p. Dissertação (Mestrado) - Universidade Federal de Viçosa.

WIERSMA, F.; SHORT, T.H. Evaporative cooling. In: HELLICKSON, M.A.; WALKER, J.N. Ventilation of agricultural structures. St. Joseph: ASAE, 1983. p.103-118.

$\overline{\text { Recebido em } 06.06 .00}$ 